\title{
Investigation into Pulse Sequence Analysis of PD features due to electrical tree growth in epoxy resin
}

DOI:

10.1109/ICD.2016.7547723

\section{Document Version}

Accepted author manuscript

Link to publication record in Manchester Research Explorer

\section{Citation for published version (APA):}

Sheng, B., Catterson, V. M., Rowland, S., \& Iddrissu, I. (2016). Investigation into Pulse Sequence Analysis of PD features due to electrical tree growth in epoxy resin. In Proceedings of the International Conference on Dielectrics 2016 https://doi.org/10.1109/ICD.2016.7547723

\section{Published in:}

Proceedings of the International Conference on Dielectrics 2016

\section{Citing this paper}

Please note that where the full-text provided on Manchester Research Explorer is the Author Accepted Manuscript or Proof version this may differ from the final Published version. If citing, it is advised that you check and use the publisher's definitive version.

\section{General rights}

Copyright and moral rights for the publications made accessible in the Research Explorer are retained by the authors and/or other copyright owners and it is a condition of accessing publications that users recognise and abide by the legal requirements associated with these rights.

\section{Takedown policy}

If you believe that this document breaches copyright please refer to the University of Manchester's Takedown Procedures [http://man.ac.uk/04Y6Bo] or contact uml.scholarlycommunications@manchester.ac.uk providing relevant details, so we can investigate your claim.

\section{OPEN ACCESS}




\section{Investigation into Pulse Sequence Analysis of PD features due to electrical tree growth in epoxy resin}

\author{
Bojie Sheng, Victoria M. Catterson \\ Institute for Energy and Environment \\ University of Strathclyde \\ Glasgow, UK \\ Bojie.sheng@strath.ac.uk
}

\author{
Simon M. Rowland, Ibrahim Iddrissu \\ School of Electronic and Electrical Engineering \\ The University of Manchester \\ Manchester, UK
}

\begin{abstract}
Electrical trees developed using point-plane samples have been investigated under three different voltage conditions: $\mathrm{AC}, \mathrm{AC}$ with positive $\mathrm{DC}$ bias, and $\mathrm{AC}$ with negative DC bias. Visual observations mainly indicate two types of electrical tree progression from initiation to breakdown: "forward and backward" (FB) trees and "forward" (F) trees. FB trees can be observed in $\mathrm{AC}$ tests, while $\mathrm{F}$ trees occur in $\mathrm{AC}$ with $\mathrm{DC}$ bias tests. The difference between $\mathrm{AC}$ with negative $\mathrm{DC}$ bias and $\mathrm{AC}$ with positive $\mathrm{DC}$ bias is the growth of a rapid long branch prior to breakdown under negative DC bias conditions. Based on the pulse sequence analysis (PSA) technique applied to the PD data associated with electrical tree growth, the findings confirm that PSA curves under different voltage tests have different regions and PSA features can be indicators of tree growth.
\end{abstract}

Keywords-Partial discharge; electrical tree; $A C$; $A C$ with $D C$ bias; pulse sequence analysis; epoxy resin

\section{INTRODUCTION}

Electrical treeing is one of the main mechanisms of longterm degradation of polymeric materials used in high voltage applications [1]. It has been found by many researchers that there is a significant relationship between partial discharge (PD) phenomena and the morphology of an electrical tree [2, 3]. Fully understanding the characteristics of PD data associated with electrical tree growth is thus key to predicting the lifetime of solid insulation and improving asset design and health management.

With increased power demand and integration of renewable energy sources, HVDC power transmission projects have been carried out in many areas around the world [4, 5]. HVDC transmission is the preferable solution for long distances. Besides supporting higher power transfer than HVAC systems it allows interconnection of systems with different frequencies $[6,7]$. Converters are applied at both ends of HVDC links, which require extensive and costly filtering of harmonics [8]. Consequently, the impact of harmonics on the reliability of DC insulation needs to be investigated. Although [8] has briefly investigated electrical trees under $\mathrm{AC}$ with $\mathrm{DC}$ bias, the relationship between electrical trees and the PD data has not yet been analyzed.

In this paper, the pulse sequence analysis (PSA) technique has been applied for PD data analysis to show distinctive features which change with the tree evolution under $\mathrm{AC}$ with DC bias. This is achieved by experimentally inducing electrical treeing in samples of epoxy resin and utilizing PSA features to identify the stage of growth under $\mathrm{AC}$ or AC with $\mathrm{DC}$ bias, which could potentially predict remaining life.

\section{METHODOLOGY}

\section{A. Experimental methodology}

In this study, the same electrical treeing samples of LY/HY 5052 epoxy resin with a gap spacing of $2 \pm 0.5 \mathrm{~mm}$ were used as in [8]. Detailed descriptions of sample preparation and the experimental plan have been outlined in [8]. The research incorporated the use of three different test voltage forms, which are an $\mathrm{AC}$ test at $15 \mathrm{kV}$ peak, AC at $15 \mathrm{kV}$ peak with $+15 \mathrm{kV}$ $\mathrm{DC}$ bias and $\mathrm{AC}$ at $15 \mathrm{kV}$ peak with $-15 \mathrm{kV} \mathrm{DC}$ bias, onto the fundamental.

During the experiment, the electrical tree was initiated under the influence of an unbiased AC voltage of between 12 and $16 \mathrm{kV}_{\mathrm{rms}}$, until a tree was evident but no longer than 50 $\mu \mathrm{m}$. Then one of the three different voltage forms was applied to the sample until breakdown occurred. During the test, PD data consisting of phase and discharge magnitude was recorded continuously, and visual images of tree growth were captured every second. In the experiments, 18 samples were randomly divided into three groups of six samples. The three different voltage tests were carried out for the three groups of samples separately.

\section{B. PSA methodology}

A governing parameter for discharges is the local electric fields, which are reflected in the change in voltage due to the excitation waveform and residual space charge from previous discharges. The basis of PSA is the investigation of correlation between consecutive discharge pulses due to the influence of local space charge generated by previous discharges on the ignition of subsequent discharge pulses [3]. As a result, this method focuses on changes to the point-on-wave external applied voltage between pulses. In this paper, PD data is analyzed according to the PSA method outlined in [9], and briefly introduced below:

1. Based on the instantaneous voltage, $u(t)$, of every PD pulse, the change of external voltage, $\Delta U_{i}$, between 
consecutive PD pulses is calculated by Equation (1). The changing pattern of $\Delta U$ can be seen clearly from the $u(t)$ plot in Figure 1.

2. The PD data is recorded in one minute batches. In order to represent the voltage change during a one minute batch, the root mean square (RMS) of the voltage change, $\Delta U_{R M S}$, is calculated using Equation (2).

3. Equation (3) is used to normalize the $\Delta U_{R M S}$ to a range between 0 and 1 .

$$
\Delta U_{i}=u\left(t_{i}\right)-u\left(t_{i-1}\right)
$$

$$
\Delta U_{r m s}=\sqrt{\frac{1}{n} \sum_{i=1}^{n} \Delta U_{i}^{2}}
$$

$$
\Delta U_{r m s(\text { Normalized }), i}=\frac{\Delta U_{r m s, i}-\Delta U_{r m s, \text { min }}}{\Delta U_{r m s, \max }-\Delta U_{r m s, \text { min }}}
$$

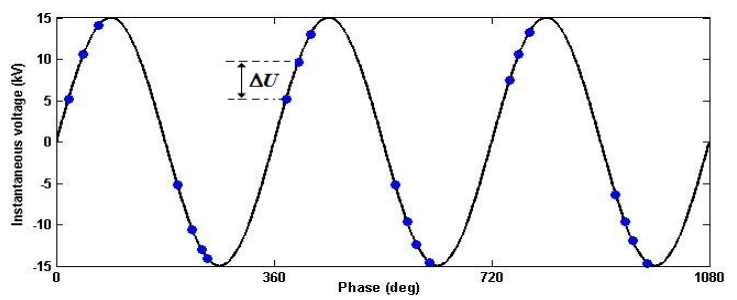

Fig. 1. The instantaneous voltage, $u(t)$, of PD occurrence

The normalized RMS of the voltage change, $\Delta U_{R M S}$, can be plotted over time to give a PSA plot of tree growth.

\section{VISUAL OBSERVATION RESULTS}

Visual observation shows that there are mainly two types of electrical tree progression from initiation to breakdown. One is defined as a "forward and backward" (FB) tree. Another is defined as a "forward" (F) tree. FB trees can be observed in every sample of epoxy resin in $\mathrm{AC}$ tests while $\mathrm{F}$ trees can be observed in every sample in AC with DC bias. But during the $\mathrm{F}$ tree progression, there is a long tree branch which occurs very rapidly in every sample in AC with negative DC bias tests while not in the AC with positive DC bias tests. It has been proposed that these differences are due to varying space charge behavior under each test condition [8]. The details of each type of tree are given below.

\section{A. Forward and backward (FB) tree}

Forward and backward (FB) trees in AC tests have three stages before breakdown, as shown in Figure 2. In the first stage, the electrical tree initially grows at the tip of the needle with a tiny bush structure, as shown in Figure 2a. Bush-type trees consist of a dense set of tubules which form from extensive branching. In the second stage, the electrical tree grows towards the counter electrode with a fine-branch structure until it fully touches the counter electrode. The branches propagate through a wide volume, as shown in Figure $2 \mathrm{~b}$, often obliquely or perpendicular to the rotational line of symmetry of the electrode system. In the third stage, one or multiple pine-branch trees are generated at the plane electrode, and propagate backwards towards the needle electrode. Compared to the fine-branch tree, the pine-branch tree has darker, apparently thicker and more heterogeneous branches, as shown in Figure 2c. The propagation speed of pine-branch trees is variable, even stagnating at some periods of time. Breakdown occurs when the pine-branch reaches the needle electrode, causing a thick channel to grow from the needle electrode to the counter electrode, and a final disruptive discharge.
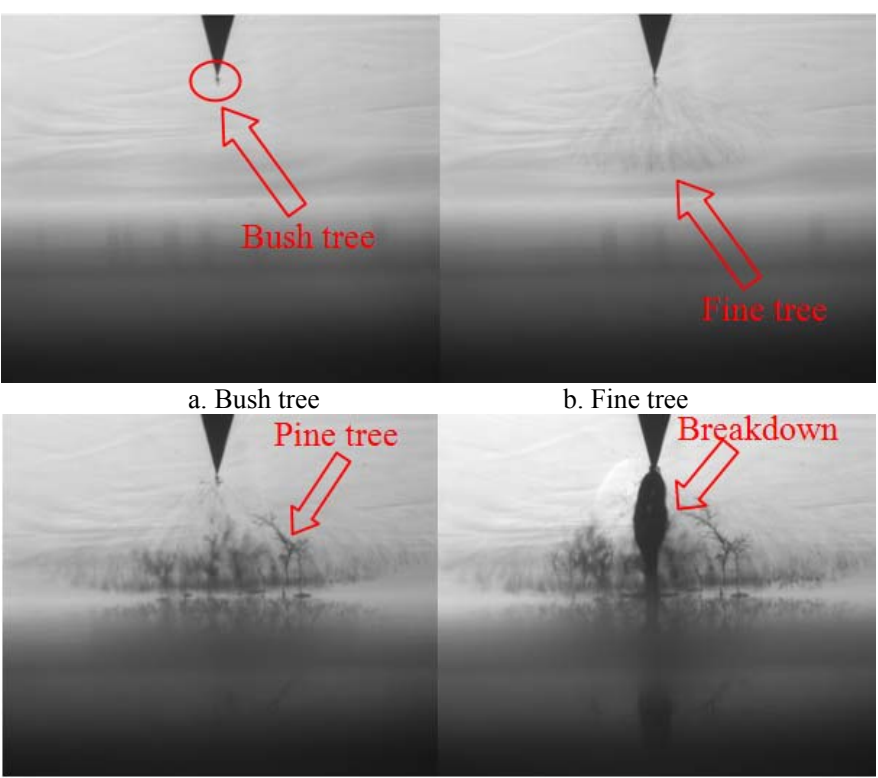

c. Pine tree

d. Breakdown

Fig. 2. Stages of the forward and backward (FB) tree.

\section{B. Forward tree}

Forward trees in AC with DC bias tests mainly have two stages before breakdown, as shown in Figure 3. The first stage appears to be the same as the first stage of the FB tree: a small bush tree initially grows at the tip of the needle, as shown in Figure 3a. In the second stage, the fine-branch tree shown in Figure $3 \mathrm{~b}$ grows towards the plane electrode. Finally, breakdown occurs after the tip of the fine-branch touches the plane electrode. Breakdown happens rapidly in the final stage.

\section{Rapid long-branch tree}

A rapid long-branch tree only occurs after the fine trees touch the plane electrode in AC with negative DC bias tests, as shown in Figure 4. This tree, as exemplified in Figure 4b, is one or two long branches which nearly bridge the space between the two conductors. The channel of the branch appears thicker than that of the fine branches, and has a darker hue. The whole branch develops rapidly, within less than one second (images were recorded once per second). Usually one or more rapid long-branch trees develop in the few minutes before breakdown. During the AC with negative DC bias tests, five out of six samples had one to three rapid long-branch trees developing within the few minutes before breakdown, while 
one sample had a lot of rapid long-branch trees which grew a long time before breakdown (nearly 120 mins before).
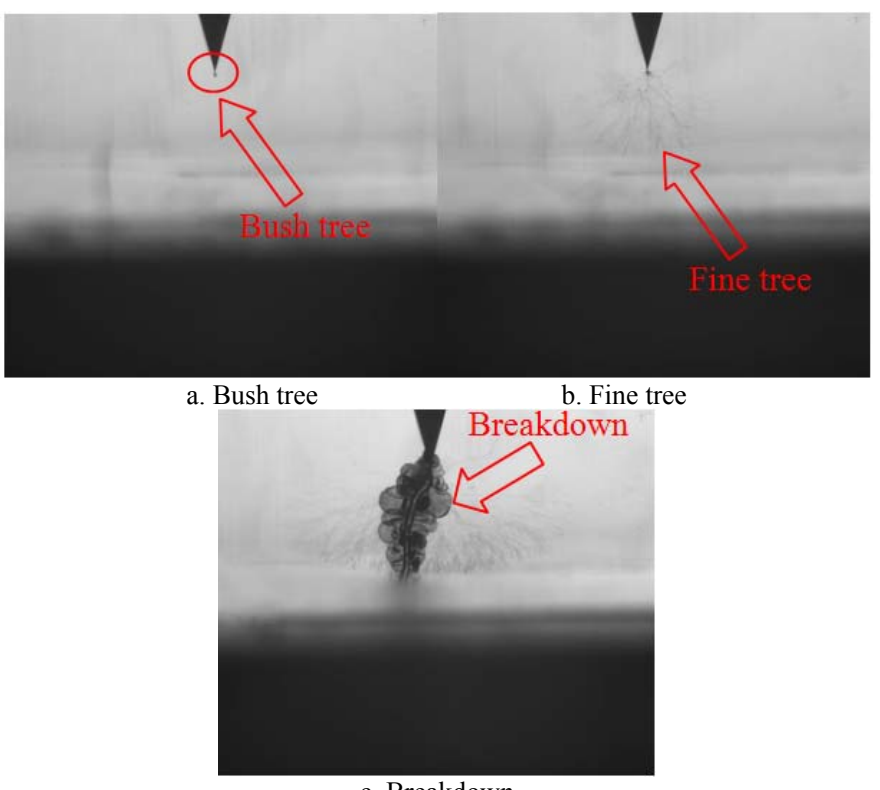

c. Breakdown

Fig. 3. Forward (F) tree.

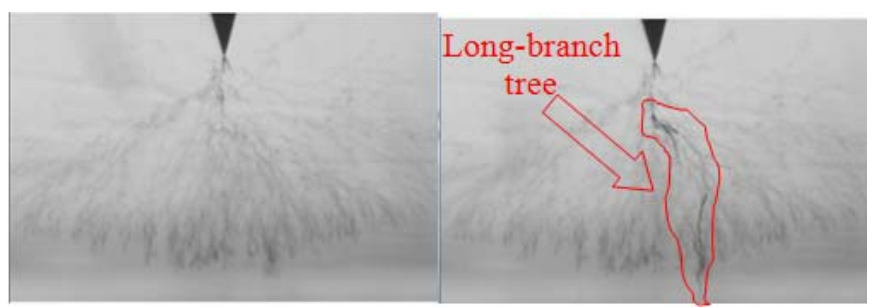

a. Three minutes before BD

b. Two minutes before $\mathrm{BD}$

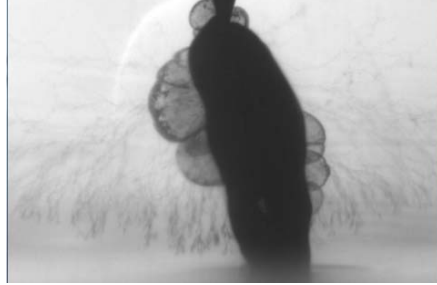

c. Breakdown (BD) time

Fig. 4. A rapid long-branch tree

\section{PSA FEATURES ASSOCIATED WITH TREE PROGRESSION}

Before the PSA analysis, a threshold of $5 \mathrm{pC}$ was applied for denoising the original PD data. Different thresholds between 0 and $10 \mathrm{pC}$ were tested, but the PSA pattern was significantly less clear for thresholds under $5 \mathrm{pC}$. Since the raw data shows true PDs below $5 \mathrm{pC}$, this threshold removes some valid data. The authors believe that PD magnitude may be a more direct indicator than PSA for this dataset. However, PSA plots of PD associated with electrical treeing from initiation to breakdown in different voltage tests are shown in Figure 5-7, and described below.

\section{A. Overall features}

1) AC tests
A typical PSA plot of an AC test sample, shown in Figure 5 , indicates three regions before breakdown. In the first region, PSA values are larger than zero. Comparison with images show this relates to the period of the small bush tree growth. Then there is a second region with no activity above $5 \mathrm{pC}$, shown as PSA values of zero in Figure 5, which is during the forward fine tree growth. Finally PSA values are larger than zero again in the third region, which results from the backward pine tree growth. Of the six AC test samples, five have these overall features. One sample (sample B8\#S1) shows activity during the second region (the reason is not known).

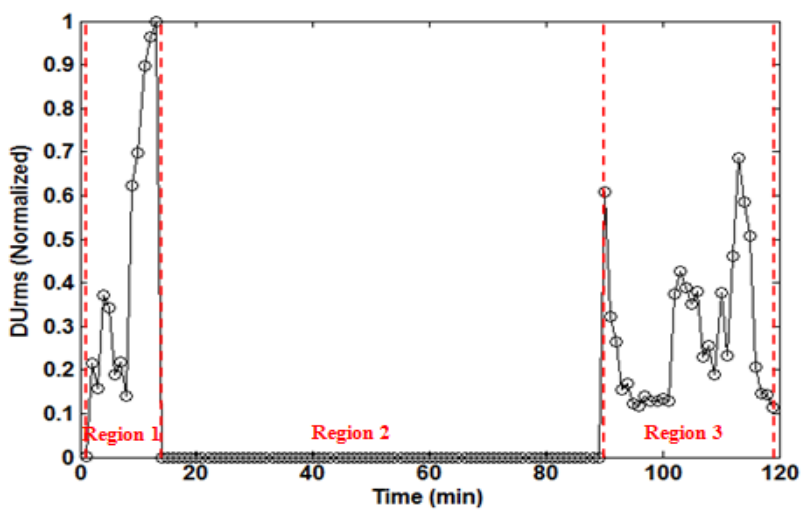

Fig. 5. PSA plot of sample B6\#S10 in AC tests

\section{2) AC with positive DC bias tests}

A typical PSA plot of an AC with positive DC bias test sample is shown in Figure 6. It indicates there are two regions before breakdown, similar to the first two regions of PSA plots in AC tests. All six samples in the AC with positive DC bias tests have PSA values larger than zero in the first region, which results during the initial small bush tree growth, and no activity above $5 \mathrm{pC}$ (represented as zero PSA values) in the second region during the forward fine tree growth.

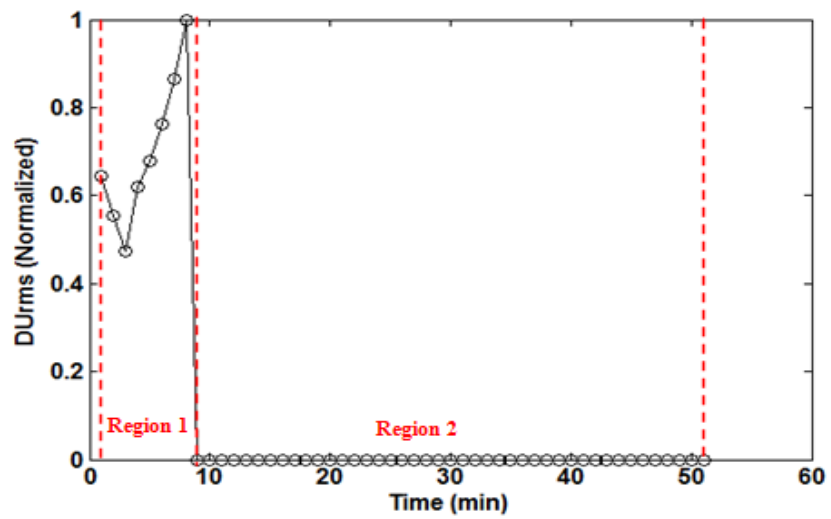

Fig. 6. PSA plot of sample B6\#S1 in AC with positive DC bias tests

\section{3) AC with negative DC bias tests}

A typical PSA plot of an AC with negative DC bias test sample is shown in Figure 7. It indicates there are two main regions before breakdown. The two regions are the same as those in the $\mathrm{AC}$ with positive DC bias tests except at the end of the second region. PSA values at the end of region two are greater than zero, due to rapid long-branch tree growth before breakdown. 


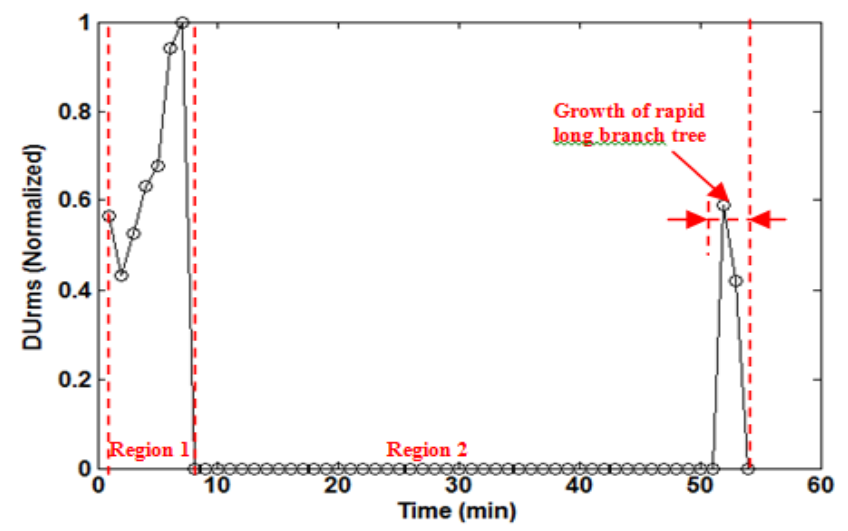

Fig. 7. PSA plot of sample B6\#S9 in AC with negative DC bias tests

\section{B. Discussion}

Given the $5 \mathrm{pC}$ threshold set for PSA analysis, this comparison of the PSA plots with the visual images indicates that bush tree discharges are larger than $5 \mathrm{pC}$; fine tree discharges are less than $5 \mathrm{pC}$ (except in one sample); and pine tree and rapid long branch discharges are larger than $5 \mathrm{pC}$. Therefore, the PSA plots generated from one minute batches of PD data can indicate what type of tree is growing, and which stage of growth has been reached. For example, as shown in Figure 8, when the PSA values increase above zero after a period of no activity, means that the backward tree has started to grow. In Figure 8 it then drops back to zero briefly, which indicates that backward tree growth has stagnated momentarily before resuming. Therefore, PSA plots might not only indicate different tree structures during the growth, but also demonstrate the propagation conditions of tree growth.

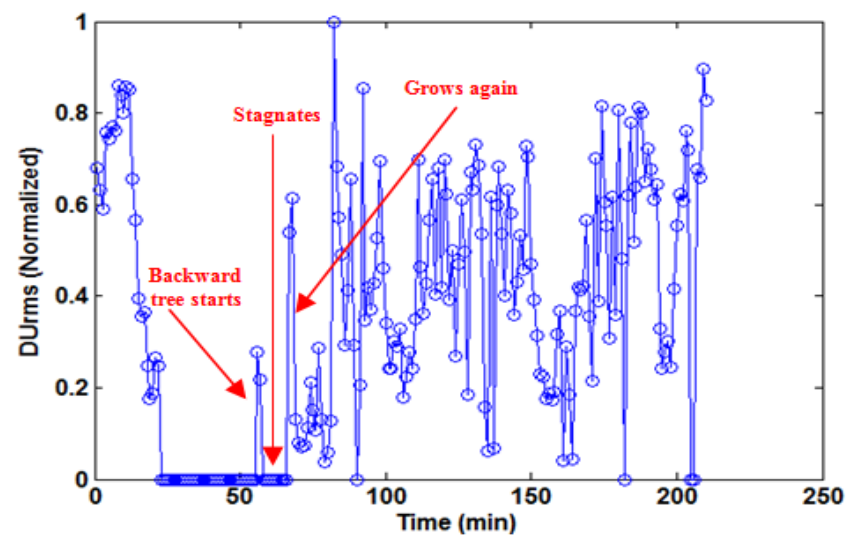

Fig. 8. PSA plot of sample B7\#S6 under an AC test

\section{CONCLUSIONS}

Visual observation of electrical trees under three different voltage waveforms (AC, $\mathrm{AC}$ with positive $\mathrm{DC}$ bias, and $\mathrm{AC}$ with negative $\mathrm{DC}$ bias) indicates two types of electrical tree progression from initiation to breakdown. One is the forward and backward (FB) tree, generated in $\mathrm{AC}$ tests, while the other is the more traditional forward $(\mathrm{F})$ tree, occurring in $\mathrm{AC}$ with $\mathrm{DC}$ bias tests. The difference between AC with negative DC bias and $\mathrm{AC}$ with positive $\mathrm{DC}$ bias is the growth of a rapid long-branch tree, which occurs before breakdown in AC with negative DC bias tests.

According to the pulse sequence analysis (PSA) of the PD data associated with electrical tree progression in different voltage tests, PSA plots could demonstrate:

a) AC tests: Have three regions which are related to the three stages of forward and backward (FB) trees before breakdown.

b) $A C$ with positive DC bias tests: Have two regions which are related to the two stages of forward (F) trees before breakdown.

c) AC with negative DC bias tests: Have two main regions with a special end region which are related to the two stages of forward $(F)$ trees plus the rapid long branch tree before breakdown.

d) PD charge level: Discharges of bush trees are larger than 5 $\mathrm{pC}$; discharges of fine trees are less than $5 \mathrm{pC}$; discharges of pine trees are larger than $5 \mathrm{pC}$; discharges of rapid long branch trees are larger than $5 \mathrm{pC}$.

Therefore, the PSA method can be applied to indicate the different electrical tree progression patterns under different voltages, and potentially used to predict remaining life.

\section{ACKNOWLEDGMENT}

The authors are grateful to the EPSRC for the financial support of this work through the project 'Towards Enhanced HVDC Cable Systems', EP/L021560/1, the 'Top \& Tail Transformation' programme grant, EP/I031707/1 (http://www.topandtail.org.uk/) and 'System Architecture Challenges: Supergen+ for HubNet' EP/M015025/1.

\section{REFERENCES}

[1] S. J. Dodd, N. M. Chalashkanov and J. C. Fothergill, "Partial discharge patterns in conducting and non-conducting electrical trees," IEEE Int. Conf. Solid Dielectrics (ICSD 2010), pp. 1-4, July 2010.

[2] S. Dodd, N. Chalashkanov, and J. Fothergill, "Partial discharge patterns in conducting and non-conducting electrical trees", in 10th IEEE Int. Conf. Solid Dielectrics (ICSD), 2010.

[3] R. Patsch and F. Berton, "Pulse sequence analysis - a diagnostic tool based on the physics behind partial discharges", Journal of Physics D: Applied Physics, vol. 35, no. 1, p. 25, 2002.

[4] K. P. Padiyar, HVDC Power Transmission Systems: Technology and Systme Interactions. New Delhi, India: Wiley \& Sons, 1990.

[5] P. Morshuis, M. Jeroense and J. Beyer, "Partial discharge, Part XXIV: The analysis of PD in HVDC equipment", IEEE Electrical Insulation Magazine, vol. 13, Issue 2, pp. 6-16, 1997.

[6] A. Cavallini, X. Chen, H. Niu and G. C. Montanari, "Strategies for PD source identification in HVDC systems", ICHVE 2008, China, pp. 649652, Nov. 2008.

[7] H. Niu, A. Cavallini, G. C. Montanari and Y. Zhang, "Noise rejection strategy and experiemtnal research on partial discharge at DC voltage", IEEE conference on the properties and applications of dielectric materials, pp. 489-492, 2009.

[8] I. Iddrissu, S. M. Rowland, "The Impact of DC Bias on Electrical Tree Growth Characteristics in Epoxy Resin Samples”, CEIDP 2015, pp.876879, 2015.

[9] N.H. Aziz, V.M. Catterson, M.D. Judd, S.M. Rowland, S. Bahadoorsingh, "Prognostic modeling for electrical treeing in solid insulation using pulse sequence analysis", CEIDP, 2014. 